\title{
Lower trait frontal theta activity in mindfulness meditators
}

\author{
Reduzida atividade teta na região frontal em praticantes de meditação mindfulness \\ Guaraci Ken Tanaka1, Caroline Peressutti,2, Silmar Teixeira ${ }^{1,2},{ }^{1}$ Mauricio Cagy ${ }^{5}$, Roberto Piedade ${ }^{1}$, Antonio \\ Egídio Nardi6,7, Pedro Ribeiro ${ }^{1,2,3}$, Bruna Velasques ${ }^{1,2,3,4}$
}

\begin{abstract}
Acute and long-term effects of mindfulness meditation on theta-band activity are not clear. The aim of this study was to investigate frontal theta differences between long- and short-term mindfulness practitioners before, during, and after mindfulness meditation. Twenty participants were recruited, of which 10 were experienced Buddhist meditators. Despite an acute increase in the theta activity during meditation in both the groups, the meditators showed lower trait frontal theta activity. Therefore, we suggested that this finding is a neural correlate of the expert practitioners' ability to limit the processing of unnecessary information (e.g., discursive thought) and increase the awareness of the essential content of the present experience. In conclusion, acute changes in the theta band throughout meditation did not appear to be a specific correlate of mindfulness but were rather related to the concentration properties of the meditation. Notwithstanding, lower frontal theta activity appeared to be a trait of mindfulness practices.
\end{abstract}

Keywords: mindfulness, meditation, EEG, frontal theta power, working memory.

\section{RESUMO}

Os efeitos agudos e de longo prazo da meditação mindfulness sobre a atividade da banda teta não são claros. 0 objetivo deste estudo foi investigar as diferenças da banda teta na região frontal entre praticantes de mindfulness iniciantes e experientes. Desta forma, vinte participantes foram recrutados (dez meditadores budistas experientes e dez não-meditadores). Apesar do aumento agudo da atividade teta durante a meditação para ambos os grupos, os meditadores apresentaram uma menor potência em ambas as condições. Sugerimos que este achado é um correlato neural da capacidade dos praticantes especialistas em limitar o processamento de informações desnecessárias e aumentar a conscientização sobre o conteúdo essencial da experiência presente. Em conclusão, as alterações agudas na banda teta durante a meditação devem estar relacionadas ao processo de concentração típico de qualquer técnica meditativa. No entanto, a atividade teta reduzida encontrada entre meditadores experientes de mindfulness parece ser uma característica desta prática específica.

Palavras-chave: mindfulness, meditação, EEG, teta frontal, memória de trabalho.

The physiology of meditation practices may depend on whether they involve concentrative mindfulness (CM) or open monitoring mindfulness (OM) as well as on the practitioner's expertise level. Experienced meditators are able to maintain the meditative state for a long time in an effortless way compared to beginners. Electroencephalographic (EEG) studies of CM have found increased activity in low-frequency bands (alpha and theta), which reflect relaxation and attentional focus, in many brain regions, including the frontal cortex $^{1-3}$. However, in long-term OM meditators, an increase in occipital ${ }^{4}$ and frontoparietal gamma activity also occurs due to their improved sensory awareness ${ }^{4}$. Evidence from long-term practitioners has also shown increased low-frequency oscillations in conjunction with gamma ${ }^{5}$. Lutz et al. ${ }^{6}$ have found an increased ratio of gamma to slow oscillatory activity $(4-13 \mathrm{~Hz})$. However, the authors did not discuss if this increased ratio was related only to higher gamma or lower slow activity or both ${ }^{6}$. Some hypotheses have been suggested,

${ }^{1}$ Institute of Psychiatry of the Federal University of Rio de Janeiro - Brain Mapping and Sensory Motor Integration - Rio de Janeiro RJ.

${ }^{2}$ Institute of Applied Neuroscience (INA) - Rio de Janeiro RJ.

${ }^{3}$ School of Physical Education of the Federal University of Rio de Janeiro (UFRJ) Bioscience Department - Rio de Janeiro RJ.

${ }^{4}$ Institute of Psychiatry of the Federal University of Rio de Janeiro - Neurophysiology and Neuropsychology of Attention - Rio de Janeiro RJ.

${ }^{5}$ Biomedical Engineering Program, of the Federal University of Rio de Janeiro (COPPE/UFRJ) - Rio de Janeiro RJ

${ }^{6}$ Institute of Psychiatry of the Federal University of Rio de Janeiro - Panic \& Respiration Laboratory - Rio de Janeiro RJ.

${ }^{7}$ National Institute of Translational Medicine (INCT-TM).

Correspondence: Guaraci Tanaka - Avenida Venceslau Brás 71 - CEP: 22290-140 Botafogo - Rio de Janeiro RJ - Brazil. E-mail: acupunturatanaka@gmail.com

Received 11 February 2014; Received in final form 18 June 2014; Accepted 08 July 2014. 
such as frontal theta (FT) activity is more engaged in CM than $\mathrm{OM}^{4}$ as well as higher frontal alpha-1 power and coherence is associated with transcendental meditation, indicating effortless meditation ${ }^{3}$.

FT activity has been described in many nonspecific situations as states of concentration, focused attention, emotion, working memory, drowsiness, and REM sleep (lower theta, 4-6 Hz) $)^{1,5,7,8}$. Thus, the studies of the cognitive processes underlying FT have been extensive, although its functions in meditation are still not clear. The mental states that are related to the practice of meditation at the beginner and experienced levels have often been correlated with increased theta activity ${ }^{9}$. However, such changes are quite unspecific because they are observed in different techniques of meditation and relaxation and during the transition to a sleep state ${ }^{5}$. Specifically, an increased FT has been observed in $\mathrm{CM}^{10,11}$, and it was defined as a sustained focus on a specific preselected object.

In contrast, OM refers to a state of sustained attention to any thought, feeling, or sensation that arises in the mind, with an attitude of acceptance and nonjudgment ${ }^{11}$. These mindfulness properties are thought to improve self-regulation and stress management by allowing individuals to refrain from trying to control the content of the mind ${ }^{12,13}$. Over the last decades, mindfulness-related treatments, such as mindfulnessbased stress reduction ${ }^{14}$ and mindfulness-based cognitive therapy $^{15}$, have been extensively researched and applied in different clinical and nonclinical populations with positive results. Notwithstanding, there is a lack of consistent reports on the regulatory mechanisms of theta oscillations in this specific meditation technique. Thus, the aim of this study was to investigate FT differences between experienced and first-time meditators before, during, and after OM. We hypothesized that long-term meditation practice would change the oscillatory pattern of the theta band in expert practitioners.

\section{METHODS}

Twenty participants were recruited. Ten were experienced meditators ( 4 men; mean \pm standard deviation age, $49.25 \pm$ 8.66), including monks and laymen from various Buddhist traditions, and ten were healthy controls (5 men; age, 41.38 $\pm 15.10)$ who never meditated. The meditators must have practiced regularly for at least the last five years (11.61 \pm 7.40 years), and all of them must have been living in the same city under the same conditions as the control group. All of the participants were medication-free and had no sensory, motor, cognitive, or attention deficits that could affect their performance. The subjects gave their written consent (in accordance with the Helsinki Declaration) to participate in the study. The experiment was approved by the Ethics Committee of the Federal University of Rio de Janeiro (IPUB/UFRJ).

\section{Task protocol}

The subjects sat with straight spines in a darkened and noise-free room to minimize sensory interference. Two meditators and one nonmeditator chose to sit on cushions on the floor, while the other participants sat on chairs. The subjects were asked to rest for 4 min (rest instructions were particularly emphasized for the meditators in order that they refrain from entering the meditative state), and then both groups started OM for $40 \mathrm{~min}$. Finally, they rested for more $4 \mathrm{~min}$ at the end. An auditory signal marked the beginning and end of each stage.

The mindfulness (OM) instruction for the meditative and nonmeditative practitioners was to "pay attention to whatever comes into your awareness. Whatever it is, a stressful thought, an emotion or body sensation, just let it pass in an effortless way, without trying to maintain it or change it in any way, until something else comes into your consciousness" ${ }^{16}$. The instructions were given immediately before the recording, as we believed this would promote higher motivation as it was a first attempt of a new activity. Due to its simplicity, the technique could be implemented, and we actually found this was particularly important. The subjects were evaluated after the task, and they reported any problems following the instructions.

\section{EEG recording}

The International 10/20 EEG electrode system (Jasper, 1958) was used witha20-channelEEG system(Braintech-3000, EMSA Medical Instruments, Brazil). The 20 electrodes were arranged on a nylon cap (ElectroCap Inc., Fairfax, VA, USA), which yielded monopolar derivation by using the earlobes as reference. The impedance of the EEG and electrooculography electrodes was kept between 5-10 k 2 . The amplitude of the recorded data was less than $70 \mu \mathrm{V}$. The EEG signal was amplified with a gain of 22,000 Hz, analogically filtered between $0.01 \mathrm{~Hz}$ (high-pass) and $80 \mathrm{~Hz}$ (low-pass), and sampled at 200 Hz. The software Data Acquisition (Delphi 5.0) from the Brain Mapping and Sensory Motor Integration Lab was employed with the notch $(60 \mathrm{~Hz})$ digital filter.

The data analysis was performed with MATLAB 5.3 (Mathworks, Inc.) and the EEGLAB toolbox (http://sccn. ucsd.edu/eeglab). We applied a visual inspection and Independent Component Analysis (ICA) to remove possible sources of artifacts that were produced by the task (i.e., blink, muscle). The data were collected with the bi-auricular reference, and they were transformed (re-referenced) with the average reference after we conducted artifact elimination with the ICA.

First, each of the trials (rest 1, meditation, rest 2) was divided into segments of 6,000 data points, which corresponded to 30-s blocks. Second, as the meditation trials lasted as long as $40 \mathrm{~min}$, we chose to analyze eight blocks ( $4 \mathrm{~min}$ ) corresponding to the moment between 30 and 34 min, which is 
consistent with the moment in which meditators recognize they are entering a deeper (concentrative) state. At that moment, we had 24 trials of 30-s blocks. A fast Fourier transform method was used to obtain the mean power amplitudes in the theta $(4-7.5 \mathrm{~Hz})$ band. The number of samples was 6,000 $(30 \mathrm{~s} \times 200 \mathrm{~Hz})$ with rectangular windowing. The absolute theta power was individually calculated on each lead every $4 \mathrm{~s}$, thus totaling 7 excerpts for each block. Thus, the total data for each group was 1,680 (24 trials $\times 7$ absolute power samples $\times$ 10 subjects). As the data was not normally distributed, a logarithmic transformation of $\log 10$ was used. Because the data did not achieve a nearly Gaussian distribution, we therefore checked it individually and decided to exclude 4 observations that showed a value above 2 times the standard deviation.

The statistical analyses of the spectral densities at the frontal sites were performed on each lead individually and averaged into a single measure of the left and right hemispheres. We used a two-way mixed design analysis of variance (group by condition) and posthoc tests with a Bonferroni correction for multiple comparisons. All of the univariate analysis of variance tests were assessed for violations of the sphericity assumption, and, when violated, they were corrected with the Huynh-Feldt method.

\section{RESULTS}

There was a statistically significant interaction between group and condition on the absolute theta power for Fp1, Fp2, F8 ( $p<0.001), F 3(p<0.015), F 4(p=0.033)$, and F7 ( $p=0.002)$. For the simple main effects result, the groups differed during rest 1 for the Fp1, F3, F4, and F8 derivations, during the meditation for the Fp1, Fp2, F3, F4, and F7 derivations, and during rest 2 for the F3, F4, F7, and F8 derivations. The FT activity was statistically significantly greater in the control group (nonmeditator) in all of the conditions, except for Fp1 during rest 1 (Tables 1 and 2).

Table 1. Statistical analyses of between groups effects.

\begin{tabular}{lc}
\hline \multicolumn{1}{c}{ Electrode } & Between group \\
\hline Fp1 & Rest 1 $F(1,478)=13.083, p<0.001$ \\
& Meditation $F(1,458)=16.916, p<0.001$ \\
Fp2 & Meditation $F(1,2.719)=48.425, p<0.001$ \\
F3 & Rest1 $F(1,497)=73.164, p<0.001$ \\
& Meditation $F(1,495)=61.827, p<0.001$ \\
& Rest 2 $F(1,498)=106.400, p<0.001$ \\
F4 & Rest $1 F(1,498)=56.954, p<0.001$ \\
& Meditation $F(1,494)=68.035, p<0.001$ \\
& Rest 2 $F(1,493)=90.399, p<0.001$ \\
F7 & Meditation $F(1,487)=7.554, p<0.006$ \\
& Rest 2 $F(1,495)=28.409, p<0.001$ \\
$F 8$ & Rest $1 F(1,491)=7.522, p<0.006$ \\
& Rest 2 $F(1,497)=36.423, p<0.001$ \\
\hline
\end{tabular}

Table 2. Absolute theta power $\left(\mu \mathrm{V}^{2} / \mathrm{Hz}\right)$ means for both groups in the three conditions

\begin{tabular}{llll}
\hline Between groups & & & \\
\hline$\mu \mathrm{V}^{2} / \mathrm{Hz}$ & Rest 1 & Meditation & Rest 2 \\
\hline Fp1 & & & \\
$\quad$ Meditator & -0.085 & -0.157 & -0.167 \\
$\quad$ Control & -0.184 & -0.07 & -0.097 \\
Fp2 & & & \\
$\quad$ Meditator & -0.062 & -0.13 & -0.12 \\
$\quad$ Control & -0.05 & 0.026 & -0.081 \\
F3 & & & \\
$\quad$ Meditator & -0.375 & -0.279 & -0.383 \\
$\quad$ Control & -0.142 & -0.045 & -0.09 \\
F4 & & & \\
$\quad$ Meditator & -0.332 & -0.226 & -0.363 \\
$\quad$ Control & -0.126 & 0.017 & -0.094 \\
F7 & & & \\
$\quad$ Meditator & -0.11 & -0.104 & -0.225 \\
$\quad$ Control & -0.082 & -0.038 & -0.095 \\
F8 & & & \\
$\quad$ Meditator & -0.164 & -0.082 & -0.229 \\
Control & -0.107 & -0.053 & -0.093 \\
\hline
\end{tabular}

Within the meditator group (MG), FT power was statistically significantly greater during the meditation compared to rests 1 and 2 for the F3, F4, F7, and F8 derivations and significantly reduced during rest 2 compared to rest 1 for the Fp1, F7, and F8 derivations (Table 3 and Figure 1). Within the control group (NMG), the FT power was statistically significantly higher during the meditation compared to rest 1 for all of the derivations studied, although it remained unchanged after the meditation (rest 2) for the Fp1 and F8 derivations (Table 3 and Figure 1).

For the averaged measure of the frontal sites, there was a statistically significant interaction between group and condition on the absolute theta power for the right $(\mathrm{p}<0.001)$ and left $(p<0.001)$ frontal hemispheres. For the simple main effects result, the groups differed at rest $1(\mathrm{p}<0.001)$, meditation $(\mathrm{p}<0.001)$, and rest $2(\mathrm{p}<0.001)$ for both hemispheres (Table 4$)$. The FT activity was significantly greater in the control group (NMG) in all of the conditions (Table 5). Within the meditator group (MG), the FT power was significantly greater during meditation compared to rest 1 and 2 for the right hemisphere and only during rest 2 for the left side. Within the control group (NMG), the FT power was significantly greater during meditation compared to the rest conditions for both hemispheres. However, there was an increase in the theta activity on the left side during rest 2 compared to during rest 1 (Tables 5 and 6, and Figure 2).

\section{DISCUSSION}

The aim of this study was to investigate whether EEG differences existed in the absolute FT powers between 
Table 3: Statistical analyses of within groups effects

\begin{tabular}{|c|c|c|c|c|}
\hline \multirow{2}{*}{$\begin{array}{l}\text { Electrodes } \\
\text { Fp1 }\end{array}$} & \multicolumn{2}{|c|}{ Within meditator group } & \multicolumn{2}{|c|}{ Within control group } \\
\hline & $p<0.017$ & $\begin{array}{l}\text { rest1 and meditation }(p=0.092) \\
\text { meditation and rest2 }(p=1.000) \\
\text { rest1 and rest2 }(p=0.007)\end{array}$ & $p<0.001$ & $\begin{array}{l}\text { rest1 and meditation }(p<0.001) \\
\text { meditation and rest2 }(p=0.463) \\
\text { rest1 and rest2 }(p<0.001)\end{array}$ \\
\hline Fp2 & $P=0.057$ & & $p<0.001$ & $\begin{array}{l}\text { rest1 and meditation }(p<0.001) \\
\text { meditation and rest } 2(p<0.001) \\
\text { rest } 1 \text { and rest2 }(p=0.329)\end{array}$ \\
\hline F3 & $p<0.001$ & $\begin{array}{l}\text { rest1 and rest2 }(p=1.00) \\
\text { rest1 and meditation }(p<0.001) \\
\text { meditation and rest } 2(p<0.001)\end{array}$ & $p<0.001$ & $\begin{array}{l}\text { rest1 and meditation }(p<0.001) \\
\text { meditation and rest } 2(p=0.013) \\
\text { rest1 and rest2 }(p<0.001)\end{array}$ \\
\hline F4 & $p<0.001$ & $\begin{array}{l}\text { rest } 1 \text { and rest2 }(p=0.214) \\
\text { rest1 and meditation }(p<0.001) \\
\text { meditation and rest } 2(p<0.001)\end{array}$ & $p<0.001$ & $\begin{array}{l}\text { rest } 1 \text { and rest2 }(p=0.057) \\
\text { rest1 and meditation }(p<0.001) \\
\text { meditation and rest } 2(p<0.001)\end{array}$ \\
\hline F7 & $p<0.001$ & $\begin{array}{l}\text { rest1 and meditation }(p=1.00) \\
\text { rest1 and rest2 }(p<0.001) \\
\text { meditation and rest } 2(p<0.001)\end{array}$ & $p<0.001$ & $\begin{array}{l}\text { rest1 and rest2 }(p=1.00) \\
\text { rest1 and meditation }(p=0.039) \\
\text { meditation and rest } 2(p=0.004)\end{array}$ \\
\hline F8 & $p<0.001$ & $\begin{array}{l}\text { rest } 1 \text { and meditation }(p<0.001) \\
\text { rest } 1 \text { and rest2 }(p=0.009) \\
\text { meditation and rest } 2(p<0.001)\end{array}$ & $p<0.004$ & $\begin{array}{l}\text { rest1 and rest2 }(p=1.00) \\
\text { meditation and rest } 2(p=0.056) \\
\text { rest1 and medit }(p=0.006)\end{array}$ \\
\hline
\end{tabular}

experienced meditators (MG) and a control group (NMG) during normal rest and OM meditation. We reported consistent interactions between the group and condition for almost all of the derivations, indicating that the level of meditation expertise (first-time vs. long-term meditators) had a differential effect on the FT power depending on the condition (rest 1 vs. meditation vs. rest 2). Our main findings will be discussed below.

An increase in FT power during meditation has been found in many studies ${ }^{10,17}$, thus supporting our findings of an increase in FT in both groups in the meditative state. The theta band in the frontal area has been associated with states of concentration, which is part of OM meditation practice. During OM, the attention is involuntary and directed to any stimulus that arises in the field of perception at any given moment. Moreover, the current information is actively maintained only until new stimuli arise, and this new perceptual processing is not affected by the previous one.

Therefore, an enhanced concentration during meditation might correlate with an increase in theta oscillations, independently of the level of expertise, if some level of concentration is reached. Perhaps the most interesting finding

Table 4: statistical analyses of between groups effects

\begin{tabular}{lc} 
Hemisphere & Between group \\
\hline Left & rest $1, F(1,1472)=11.403, p<0.001$ \\
& $\begin{array}{l}\text { meditation } F(1,1444)=73.257, p<0.001 \\
\text { rest } 2 F(1,1472)=94.981, p<0.001\end{array}$ \\
Right & rest $1 F(1,1485)=28.600, p<0.001$ \\
& $\begin{aligned} \text { meditation } F(1,1459)=94.688, p<0.001 \\
\text { rest } 2 F(1,491)=72.526, p<0.001\end{aligned}$ \\
\hline
\end{tabular}

of the present study was that, although an acute increase in theta activity during meditation was seen in both groups, the meditators showed a lower trait FT. Because meditation improves attention and concentration, constant training in OM limits the overuse of working memory ${ }^{18}$, and, therefore, it may be associated with the lower levels of FT observed in the MG compared to the NMG. We suggested that this finding was a neural correlate of the expert practitioners' ability to limit the processing of unnecessary information (e.g., discursive thought) and increase awareness of the essential content of the present experience with an attitude of acceptance. According to Chiesa et al. ${ }^{19}$, this is a clear description of a bottom-up regulatory process.

Furthermore, attention is also thought to act as a gate to working memory ${ }^{20}$. Thus, theta band increases in the frontal area have been associated with the active maintenance of working memory representations ${ }^{8,21-23}$ and this relevant information in an active state has influence on future perceptual processing, thought, and behavior ${ }^{20}$. Thereby, in this study, the NMG was unaware of OM (new processing) despite the clear instructions that had been given just before the task. This processing generated an increase in mental activity, and a high perceptual process load can impair the ability to detect stimuli in environments that overload the working memory ${ }^{24}$. It might worsen attention and concentration, resulting in a decrease in vigilance and an increase in mental effort when associated with another low frequency, such as alpha ${ }^{25}$, and this may partly explain our findings.

Another important finding was that we did not find a significant difference between the rest conditions and meditation at the prefrontal derivations (Fp1, Fp2) in the MG. The finding that the activation level in the prefrontal area remained constant for the meditators, whether they were meditating or not, was an indicator that the ability of these subjects to control 

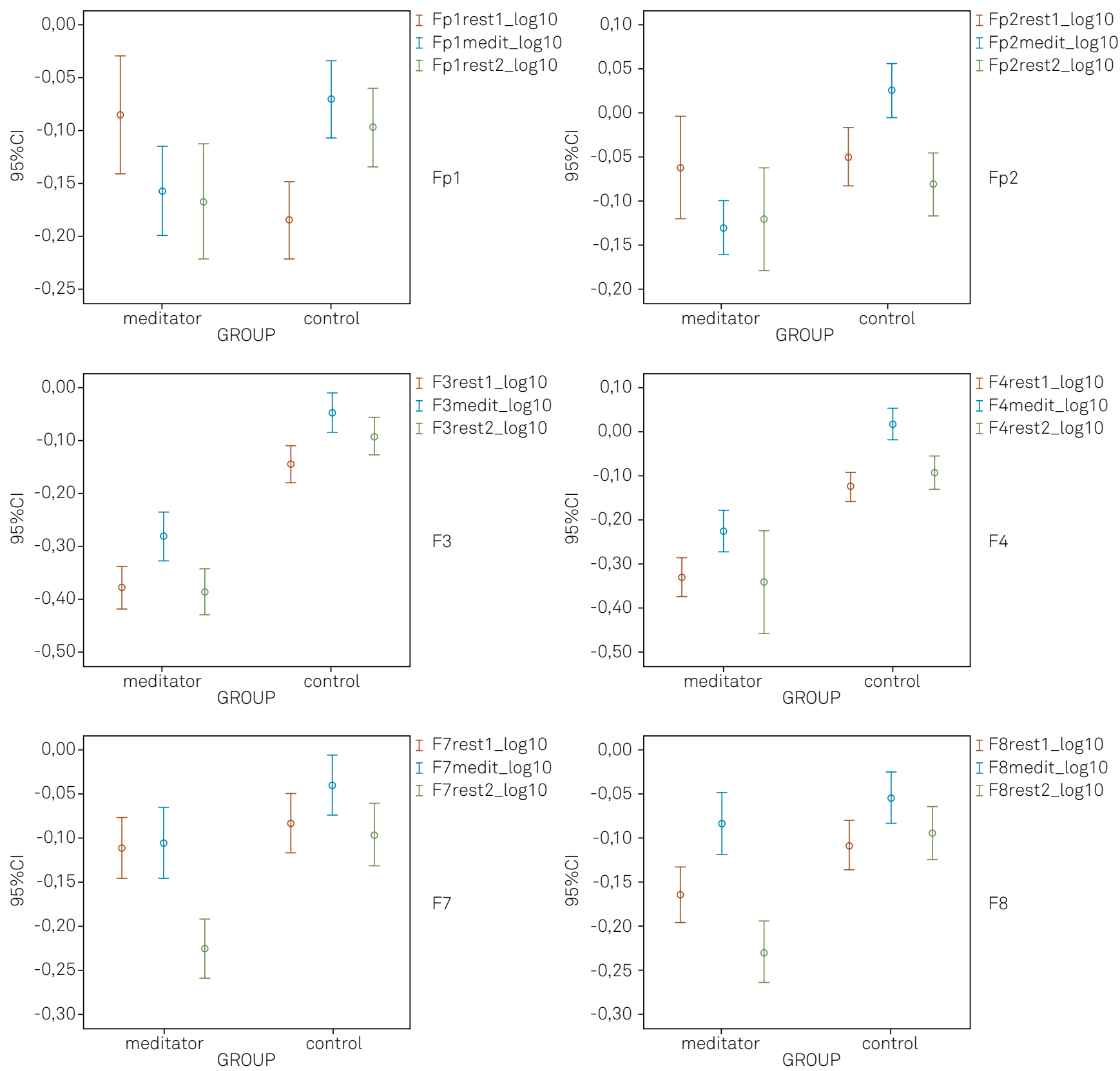

Figure 1. Profile plots of significant absolute theta power at frontal areas $\left(\mu \mathrm{V}^{2} / \mathrm{Hz}\right)$.

their narrative focus was not exclusive of formal meditation. The typical narrative focus (e.g., discursive thought) impairs attentional performance and involves mental elaboration and evocation, which overload the working memory processing. The prefrontal cortex (PFC) is responsible for the coordination of all of this mental traffic in working memory, and mindfulness training possibly enhances the ability of the PFC to maintain high attention levels outside of formal meditation ${ }^{26}$. This is clearly a top-down process, which involves the executive control of attention and the modulation of emotional limbic structures ${ }^{19}$. Therefore, it is clear that, although bottom-up processes explain in part the role of mindfulness as an emotion regulation strategy ${ }^{19}$, there are also top-down processes that are important in regulating attention.

Table 5: Absolute theta power $\left(\mu \mathrm{V}^{2} / \mathrm{Hz}\right)$ means for both groups in the three conditions

\begin{tabular}{lllllll}
\hline $\boldsymbol{\mu} \mathbf{V}^{\mathbf{2}} / \mathbf{H z}$ & \multicolumn{3}{c}{ Right frontal } & \multicolumn{3}{c}{ Left frontal } \\
& Rest 1 & Medit & Rest 2 & Rest 1 & Medit & Rest 2 \\
Meditator & -0.185 & -0.148 & -0.236 & -0.185 & -0.184 & -0.247 \\
Control & -0.97 & -0.004 & -0.094 & -0.129 & -0.043 & -0.086 \\
\hline
\end{tabular}


Table 6: statistical analyses of within groups effects

\begin{tabular}{lccc}
\hline Electrodes & Within meditator group & Within control group \\
\hline Left & $p<0.001$ & $\begin{array}{c}\text { rest1 and meditation }(p=0.873) \\
\text { meditation and rest2 }(p<0.001) \\
\text { rest1 and rest2 }(p<0.001)\end{array}$ & $\begin{array}{c}\text { rest1 and meditation }(p<0.001) \\
\text { meditation and rest2 }(p<0.001) \\
\text { rest1 and rest2 }(p<0.001)\end{array}$ \\
Right & $\begin{array}{r}\text { rest1 and meditation }(p=0.014) \\
\text { meditation and rest2 }(p<0.001) \\
\text { rest1 and rest2 }(p<0.001)\end{array}$ & $\begin{array}{c}\text { rest1 and meditation }(p<0.001) \\
\text { meditation and rest2 }(p<0.001) \\
\text { rest1 and rest2 }(p=1.00)\end{array}$ \\
\hline
\end{tabular}

Chiesa et al. ${ }^{19}$ have suggested that mindfulness training is associated with bottom-up emotional regulation in long-term practitioners and with top-down emotional regulation in short-term practitioners according to different conceptions of mindfulness as an emotional regulation strategy. However, we suggest that top-down processing is also present in experienced practitioners, although it is reduced as bottom-up processing becomes emphasized. The top-down processing facilitates positive reappraisal, thus recruiting PFC regions that are associated with emotional reappraisal ${ }^{19,27,28}$. This is in accordance with our findings because the NMG significantly increased their left prefrontal activity during meditation (with only brief meditation instructions), which was probably related to the better executive control of attention, including positive reappraisal, as this area of the cortex has been linked to positive affect ${ }^{29,30}$. Indeed, these subjects maintained greater activity at the left PFC (Fp1) during rest 2, which can be associated with an increased mood that persists after meditation.

When we averaged the frontal sensors into a single measure of the left and right hemispheres, we found similar results in comparison to the individual prefrontal electrodes for the NMG. For the MG, we also did not find a significant difference between rest 1 and meditation in the left hemisphere for Fp1 (left prefrontal). These results possibly indicated an important role of the PFC in coordinating attention and emotion regulation processes in the MG. This top-down processing was more emphasized in the NMG,

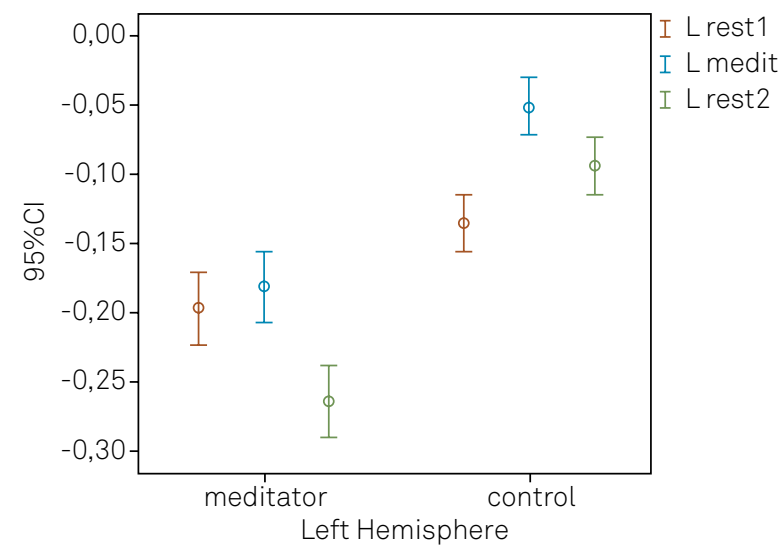

although it was still important for the long-term meditators (MG). We suggest, based on the evidence of the emotion asymmetry in the $\mathrm{PFC}^{30}$, that the top-down regulation of positive reappraisal was related to left PFC activity, which was increased in meditators at rest and increased during meditation for the NMG. Our findings were consistent with the mindfulness-related present-moment focus, which is thought to improve well-being by allowing individuals to refrain from trying to control the content of the mind and to become aware of sensations, emotions, and thoughts without judgment or reactivity ${ }^{31}$.

In summary, many differences were found in this study. As we expected, long-term meditation practice altered the oscillatory pattern of the theta band, which has been associated with cognitive functions, such as executive attention and working memory. Despite the acute increase in theta activity during meditation in both groups, the meditators showed a lower trait FT. This was consistent with a reduced top-down control of attention and an increased present moment awareness. In conclusion, acute changes in the theta band throughout meditation did not seem to be a specific correlate of OM, but it was rather related to the concentration properties of meditation. Notwithstanding, lower FT activity appeared to be a trait of OM practice. The present study did not analyze the ratio of gamma-band activity $(25-42 \mathrm{~Hz})$ to slow oscillatory activity (4-13 Hz), which could be enlightening. Further research is encouraged to evaluate the electrophysiological correlates of OM meditation. 
1. Lagopoulos J, Xu J, Rasmussen I, et al. Increased Theta and Alpha EEG Activity. J Altern Complement Med 2009;15:1187-1192.

2. Baijal S, Srinivasan N. Theta activity and meditative states: spectral changes during concentrative meditation. Cogn Process 2010;11:31-38.

3. Travis F, Shear J. Focused attention, open monitoring and automatic self-transcending: categories to organize meditations from Vedic, Buddhist and Chinese traditions. Conscious Cogn 2010;19:1110-1118.

4. Cahn BR, Delorme A, Polich J. Occipital gamma activation during Vipassana meditation. Cogn Process 2010;11:39-56.

5. FellJ,Axmacher N, HauptS. Fromalphatogamma:electrophysiological correlates of meditation-related states of consciousness. Med Hypotheses Res 2010;75:218-224.

6. Lutz A, Greischar LL, Rawlings NB, Ricard M, Davidson RJ. Long-term meditators self-induce high-amplitude gamma synchrony during mental practice. Proc Natl Acad Sci USA 2004;101:16369-1673.

7. Mitchell DJ, McNaughton N, Flanagan D, Kirk IJ. Frontal-midline theta from the perspective of hippocampal "theta". Prog Neurobiol 2008;86:156-185.

8. Itthipuripat S, Wessel JR, Aron AR. Frontal theta is a signature of successful working memory manipulation. Exp Brain Res 2013;224:255-262.

9. Takahashi T, Murata T, Hamada T, et al. Changes in EEG and autonomic nervous activity during meditation and their association with personality traits. Int J Psychophysiol 2005;55:199-207.

10. Cahn BR, Polich J. Meditation states and traits: EEG, ERP, and neuroimaging studies. Psychol Bull 2006;132:180-211.

11. Lutz A, Slagter HA, Dunne JD, Davidson RJ. Attention regulation and monitoring in meditation. Trends Cogn Sci 2008;12:163-169.

12. Colzato LS, Ozturk A, Hommel B. Meditate to create: the impact of focused-attention and open-monitoring training on convergent and divergent thinking. Front Psychol 2012;3:116.

13. Perlman DM, Salomons TV, Davidson RJ, Lutz A. Differential effects on pain intensity and unpleasantness of two meditation practices. Emotion 2010;10:65-71.

14. Kabat-zinn J. Full catastrophe living: using the wisdom of your body and mind to face stress, pain and illness. New York: Delta; 1990.

15. Teasdale JD, Segal Z V, Williams JMG, Ridgeway VA, Soulsby JM, Lau MA. Prevention of relapse/recurrence in major depression by mindfulness-based cognitive therapy. J Consult Clin Psychol 2000;68:615-623.

16. Brewer JA, Worhunsky PD, Gray JR, Tang YY, Weber J, Kober H. Meditation experience is associated with differences in default mode network activity and connectivity. Proc Natl Acad Sci USA 2011;108:20254-20259.
17. Berkovich-Ohana A, Glicksohn J, Goldstein A. Mindfulness-induced changes in gamma band activity - implications for the default mode network, self-reference and attention. Clin Neurophysiol 2012;123:700-710.

18. Jha AP, Stanley EA, Kiyonaga A, Wong L, Gelfand L. Examining the protective effects of mindfulness training on working memory capacity and affective experience. Emotion 2010;10:54-64.

19. Chiesa A, Serretti A, Jakobsen JC. Mindfulness: top-down or bottomup emotion regulation strategy? Clin Psychol Rev 2013;33:82-96.

20. Sala JB, Courtney SM. Flexible working memory representation of the relationship between an object and its location as revealed by interactions with attention. Atten Percept Psychophys 2010;71:1525-1533.

21. Jensen $\mathrm{O}$, Tesche CD. Short communication frontal theta activity in humans increases with memory load in a working memory task. Eur J Neurosci 2002;15:1395-1399.

22. Benchenane K, Tiesinga PH, Battaglia FP. Oscillations in the prefrontal cortex: a gateway to memory and attention. Curr Opin Neurobiol 2011;21:475-485.

23. Roberts BM, Hsieh LT, Ranganath C. Oscillatory activity during maintenance of spatial and temporal information in working memory. Neuropsychologia 2013;51:349-357.

24. Norman G. Working memory and mental workload. Adv Health Sci Educ Theory Pract 2013;18:163-165.

25. Kamzanova T, Kustubayeva M, Matthews G. Use of EEG workload indices for diagnostic monitoring of vigilance decrement. Hum Factors J Hum Factors Ergon Soc 2012;56:203-207.

26. Slagter H, Davidson RJ, Lutz A. Mental training as a tool in the neuroscientific study of brain and cognitive plasticity. Front Hum Neurosci 2011;5:17.

27. Ochsner KN, Gross JJ. The cognitive control of emotion. Trends Cogn Sci 2005;9:242-249.

28. Rolls ET, Grabenhorst F. The orbitofrontal cortex and beyond: from affect to decision-making. Prog Neurobiol 2008;86:216-244.

29. Aftanas LI, Golocheikine S. Human anterior and frontal midline theta and lower alpha reflect emotionally positive state and internalized attention: high-resolution EEG investigation of meditation. Neurosci Lett 2001;310:57-60.

30. Davidson RJ. Anterior cerebral asymmetry and the nature of emotion. Brain Cogn 1992;20:125-151.

31. Kerr CE, Sacchet MD, Lazar SW, Moore Cl, Jones SR. Mindfulness starts with the body: somatosensory attention and top-down modulation of cortical alpha rhythms in mindfulness meditation. Front Hum Neurosci 2013;7:12. 